\title{
Inhibitory Effect of Chunghyuldan in Prostaglandin E2 and Nitric Oxide Biosynthesis of Lipopolysaccharide-Induced RAW 264.7 Cells
}

\author{
Ki-Ho ChO, ${ }^{a}$ Young-Suk Kim, ${ }^{a}$ Hyung-Sup BAE,,${ }^{a}$ Sang-Kwan Moon, ${ }^{a}$ Woo Sang Jung, ${ }^{a}$ \\ Eun-Kyung PARK, ${ }^{b}$ and Dong-Hyun $\mathrm{KIM}^{*}, b$ \\ ${ }^{a}$ College of Oriental Medicine, Kyung Hee University; and ${ }^{b}$ College of Pharmacy, Kyung Hee University; 1, Hoegi, \\ Dongdaemun-ku, Seoul 130-701, Korea. Received April 13, 2004; accepted August 2, 2004
}

\begin{abstract}
Chunghyuldan (Daio-Orengedokuto in Japanese) (CHD) has been used as an antihyperlipidemic and antiischemic agent in Korea. To evaluate in vitro the efficacy of Chunghyuldans (CHDs) metabolized with and without human intestinal microflora against brain ischemia, we investigated its anti-inflammatory effect on LPS-induced RAW264.7 cells. Both metabolized CHD (MCHD) and CHD showed antioxidant activities in vitro, and inhibited nitric oxide (NO) and prostaglandin E2 (PGE2) productions in lipopolysaccharide (LPS)-induced RAW264.7 cells. These also inhibited enzyme activities and protein expressions of inducible NO synthase and cyclooxygenase-2 in LPS-induced RAW264.7 cells. MCHD-inhibitory activity against NO and PGE2 productions in LPS-induced RAW264.7 cells was more potent than those of CHD. These results suggest that CHD may show potent anti-inflammatory activity in vivo and can improve brain ischemia.
\end{abstract}

Key words Chunghyuldan; Daio-Orengedokuto; nitric oxide; prostaglandin E2; cyclooxygenase (COX)-2; ischemia

An inflammatory reaction in the brain, due to intervention or decrease of blood circulation, causes an ischemic stroke, and occurs in about $80 \%$ of brain stroke patients. ${ }^{1,2)}$ The damage to brain neuronal cells due to an inflammatory reaction causes the release of excessive excitational neuronal transmitters, production of free radicals, inhibition of protein synthesis, abnormal expression of genes and the activation of immune responses. The inflammatory responses are mainly modulated by activated neutrophils and macrophages. Nitric oxide (NO) and prostaglandins are two pleiotropic mediators produced at inflammatory sites by the enzymes constitutive and inducible NO synthases and cyclooxygenase (COX)-1 and COX-2. ${ }^{3)}$ Stimuli such as cytokines and/or bacterial lipopolysaccharide (LPS) induce inducible NO synthase (iNOS) protein expression, and once synthesized, iNOS is responsible for the prolonged, high-output production of NO. Despite its beneficial role in host defense, sustained NO production can be deleterious to the host, and has been implicated in the pathogenesis of various inflammatory diseases. ${ }^{4,5)} \mathrm{COX}$, which catalyzes the conversion of arachidonic acid to prostaglandin (PGE2), is a rate-limiting enzyme in the biosynthesis of prostaglandins. ${ }^{6,7)} \mathrm{COX}-2$ is rapidly induced after stimulation with cytokines and/or lipopolysaccharide (LPS) ${ }^{8)}$ COX-2 is predominantly expressed in cells involved in inflammatory reactions. iNOS and COX-2 gene expressions are regulated by transcription factors, such as NF- $\kappa$ B transcription factor, on RAW 264.7 cell stimulated with LPS.

Chunghyuldan (Daio-Orengedokuto in Japanese), which consists of Scutellariae Radix, Coptidis Rhizoma, Phellodendri Cortex, Gardeniae Fructus and Rhei Rhizoma, is known to have antihyperlipidemic as well as antiischemic activities, and has been used for patients with atherosclerosis and brain ischemic brain injury. ${ }^{9-11)}$

To evaluate in vitro the efficacy of Chunghyuldans (CHDs) metabolized with and without human intestinal microflora against brain ischemia, we investigated its anti-inflammatory effect on LPS-induced RAW264.7 cells.

\section{MATERIALS AND METHODS}

Materials $N^{\mathrm{G}}$-Monomethyl-L-arginine (L-NMMA), LPS, caffeic acid, allopurinol and indomethacin were all purchased from Sigma Chemical Co. (U.S.A). The Griess reagent was purchased from Promega Co. (U.S.A.). The PGE2 enzyme immunoassay kit and bovine COX Inhibitor Screening Assay kits were purchased from Cayman Chemical (U.S.A.).

Chunghyuldan (CHD) was prepared according to the previous method. ${ }^{9)}$ It consists of $80 \%$ EtOH extracts of Coptidis Rhizoma 4 g, Phellodendri Cortex 4 g, Scutellariae Radix 4 g, Gardeniae Fructus 4 g, and Rhei Rhizoma 4 g.

Metabolized CHD (MCHD) was prepared by incubating CHD with intestinal microflora as follows. CHD $(2 \mathrm{~g})$ was incubated with human intestinal bacteria at $37^{\circ} \mathrm{C}$ for $24 \mathrm{~h}$, extracted with ethyl acetate and concentrated. To use CHD as a test sample in the present study, it also extracted with ethyl acetate and concentrated. Each concentrate was used as MCHD or CHD sample. CHD contained $1.2 \%$ berberine, $0.1 \%$ baicalein and $1.5 \%$ baicalin when determined by HPLC. MCHD contained $0.9 \%$ berberine, $1.1 \%$ baicalein and $0.2 \%$ baicalin.

Assay of Antioxidant Activities The 1,1-diphenyl-2picrylhydrazyl (DPPH) radical scavenging, superoxide anion radical generation and xanthine oxidase-inhibitory activities of CHD and MCHD were measured according to the method of Xiong et al. ${ }^{12)}$

Assay of Nitric Oxide The nitric oxide was determined by measuring the amount of nitrite in the cell culture supernatant using Griess reagent according to the manufacturer's protocol. ${ }^{13)}$ The RAW 264.7 cells were stimulated with LPS $(1 \mu \mathrm{g} / \mathrm{ml})$ and test agents for $24 \mathrm{~h}$, and briefly centrifuged and $150 \mu \mathrm{l}$ of cell culture supernatant were mixed with $150 \mu \mathrm{l}$ of Griess reagent, and incubated for $10 \mathrm{~min}$ at room temperature (light protected). The absorbance was measured using an ELISA reader at $540 \mathrm{~nm}$ and compared to a standard calibration curve prepared from sodium nitrite.

Assay of PGE2 The RAW 264.7 cells were seeded at $5 \times 10^{4}$ cells per well in flat-bottomed 96 -well plates. The test 
agents and LPS $(1 \mu \mathrm{g} / \mathrm{ml})$ were added to the culture medium, and incubated at $37^{\circ} \mathrm{C}$ for $20 \mathrm{~h}$. The medium was collected in a microfuge tube and then centrifuged at $2800 \times \boldsymbol{g}$ for $10 \mathrm{~min}$. The supernatant was decanted into a new microfuge tube, and the amount of PGE2 determined using a PGE2 Enzyme-Immuno-Assay kit (Cayman Chemical, U.S.A.).

Measurement of iNOS Activity The RAW 264.7 cells were stimulated with LPS $(1 \mu \mathrm{g} / \mathrm{ml})$ for $16 \mathrm{~h}$, and the cells washed twice with PBS. They were then incubated with test agents or L-NMMA for $16 \mathrm{~h}$. Cells were briefly centrifuged and $150 \mu \mathrm{l}$ of the supernatant mixed with $150 \mu \mathrm{l}$ of Griess reagent, and incubated $10 \mathrm{~min}$ at room temperature (light protected). The absorbance was measured using an ELISA reader at $540 \mathrm{~nm}$, and compared to a standard calibration curve prepared from sodium nitrite. ${ }^{13)}$

Measurement of COX-2 Activity RAW 264.7 cells were seeded at $5 \times 10^{4}$ cells per well in flat bottomed 96-well plates. Cells were stimulated with LPS $(1 \mu \mathrm{g} / \mathrm{ml})$ for $16 \mathrm{~h}$ to induce COX-2. The cells were washed twice with fresh culture medium and incubated with test agents for $10 \mathrm{~min}$. The cells were further incubated for $40 \mathrm{~min}$ in medium with $30 \mu \mathrm{M}$ arachidonic acid. The supernatants were removed and assayed for prostaglandin E2 as described above.

Western Blot Analysis of iNOS, COX-2 and NF- $\kappa \mathrm{B}$ in LPS-Induced RAW 264.7 Cells Western blot analyses of the iNOS, COX-2 and NF- $\kappa \mathrm{B}$ were performed according to the method of Ishihara et al. ${ }^{14)}$ The RAW 264.7 cells were plated in $60 \mathrm{~mm}$ culture dishes $\left(3 \times 10^{6}\right.$ cells $)$, test agents and LPS $(1 \mu \mathrm{g} / \mathrm{ml})$ added to the culture medium, and the cells incubated at $37^{\circ} \mathrm{C}$ for $6-20 \mathrm{~h}$. The cells were lysed on ice for $15 \mathrm{~min}$ in an hypotonic buffer, containing $10 \mathrm{~mm}$ Tris (pH 8.0), $1.5 \mathrm{~mm} \mathrm{MgCl}_{2}, 1 \mathrm{~mm}$ DTT, $0.1 \% \mathrm{NP}-40,5 \mu \mathrm{g} / \mathrm{ml}$ pepstatin $\mathrm{A}$ and $5 \mu \mathrm{g} / \mathrm{ml}$ aprotinin, and centrifuged at $12000 \times \boldsymbol{g}$ and $4{ }^{\circ} \mathrm{C}$ for $15 \mathrm{~min}$. The supernatant was used as the cytosol fraction for the Western blot assays for the iNOS and COX-2 protein expressions. The pelleted nuclei fractions for the Western blot assays of the NF- $\kappa \mathrm{B}$ protein expression were resuspended in the extraction buffer, containing $10 \mathrm{~mm}$ Tris ( $\mathrm{pH} 8.0$ ), $50 \mathrm{~mm} \mathrm{KCl,} 300 \mathrm{~mm} \mathrm{NaCl}, 1 \mathrm{~mm}$ DTT, $5 \mu \mathrm{g} / \mathrm{ml}$ pepstatin $\mathrm{A}$ and $5 \mu \mathrm{g} / \mathrm{ml}$ aprotinin, and then lysed on ice for $30 \mathrm{~min}$. The lysed nuclei fraction was centrifuged at $12000 \times \boldsymbol{g}$ and $4{ }^{\circ} \mathrm{C}$ for $30 \mathrm{~min}$. The cell lysates $(40 \mu \mathrm{g})$ were separated by sodium dodecyl sulfate-polyacrylamide gel electrophoresis (SDS-PAGE) under reducing conditions, and transferred to polyvinylidene difluoride (PVDF) membranes (Millipore, Hertfordshire) at $30 \mathrm{~V}$ for $2 \mathrm{~h}$. The membranes were blocked with $2 \%$ skim milk in PBS, containing $0.05 \%$ tween 20, and incubated for $2 \mathrm{~h}$ at room temperature, and for a further $2 \mathrm{~h}$ with anti-iNOS, anti-COX-2, anti-NF- $\kappa \mathrm{B}$ antibodies as primary antibodies. After removing the primary antibodies, the membranes were washed three times with phosphated buffered saline (PBS), containing 0.05\% tween 20, and then incubated with a 1:2000 dilution of the secondary antibody conjugated to horseradish peroxidase for $1 \mathrm{~h}$. The membranes were washed three times, and reaction products visualized using an ECL Western blot system.

Statistical Analysis All the data from the in vivo experiments were expressed as mean \pm S.D. and statistical significance was determined using Student's $t$-test.

\section{RESULTS}

Active Oxygen Radical Scavenging Activities of CHD and MCHD The components of these herbal medicines orally administered are therefore inevitably brought into contact with intestinal microflora in the alimentary tract and can be transformed before they were absorbed from the gastrointestinal tract. Therefore, to understand the pharmacological effects of CHD orally administered, we incubated it with human intestinal microflora and extracted with ethyl acetate. And then active oxygen radical scavenging activities of CHDs was measured (Table 1). Active oxygen radical scavenging activities superoxide radical scavenging and lipid peroxidation-inhibitory activities of MCHD were more potent than those of nontreated CHD. Main components of intact CHD was berberine, baicalin and chrysophanol glycoside. However, main components of metabolized CHD (MCHD) was berberine, baicalein and chrysophanol. Thus, glycosides of CHD was transformed to their aglycones.

Effect of CHDs on NO and PGE2 Production of the Murine Macrophage Cells Induced by LPS To evaluate the antiinflammatory effects of CHDs, their inhibitory effects on NO and PGE2 production in LPS-stimulated cultures of the murine macrophages of the RAW 264.7 cells were examined. The stimulation of the RAW 264.7 cells with LPS induced NO production (Fig. 1). However, both MCHD and $\mathrm{CHD}$ at concentrations of 10 and $50 \mu \mathrm{g} / \mathrm{ml}$ weakly inhibited NO production in LPS-stimulated RAW 264.7 cells. However, the difference between MCHD and CHD was not significant. Stimulation of the RAW 264.7 cells with the LPS

Table 1. Antioxidant and Anti-lipid Peroxidation Activities of CHD and $\mathrm{MCHD}$

\begin{tabular}{lccc}
\hline \hline & \multicolumn{3}{c}{$\mathrm{IC}_{50}(\mu \mathrm{g} / \mathrm{ml})$} \\
\cline { 2 - 4 } & $\left.\mathrm{DPPH}^{a}\right)$ & $\mathrm{XO}^{b)}$ & $\mathrm{SO}^{c)}$ \\
\hline CHD & 8 & $>50$ & 16 \\
MCHD & 6 & 48 & 12 \\
Caffeic acid & 4 & $\left.-{ }^{d}\right)$ & 0.5 \\
Allopurinol & - & 40 & -
\end{tabular}

Each data represents the mean of triplicate experiments. a) DPPH (1,1-diphenyl-2 picrylhydrazyl) free radical scavenging assay. b) Xanthine oxidase inhibitory assay. c) Superoxide anion scavenging assay. d) Not determined. CHD, Chunghyuldan; MCHD, metabolized Chunghyuldan;.

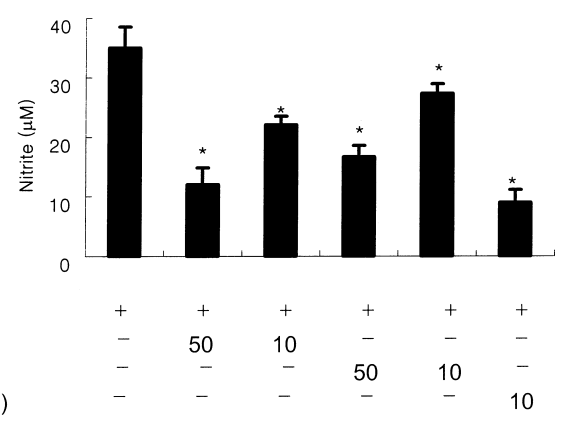

Fig. 1. Inhibitory Effect of CHD and MCHD on NO Production of LPSStimulated RAW 264.7 Cellls

The RAW 264.7 cells were stimulated with LPS $(1 \mu \mathrm{g} / \mathrm{ml})$ and test agents for $24 \mathrm{~h}$, and briefly centrifuged. NO contents of the resulting supernatant were measured by Griess reagent. LPS, lipopolysaccharide; MC, metabolized Chunghyuldan; C Chunghyuldan; L-NMMA, $N^{\mathrm{G}}$-monomethyl-L-arginine. All values are means \pm S.D. $(n=3)$. * Significantly different from LPS-stimulated group $(p=0.05)$. 


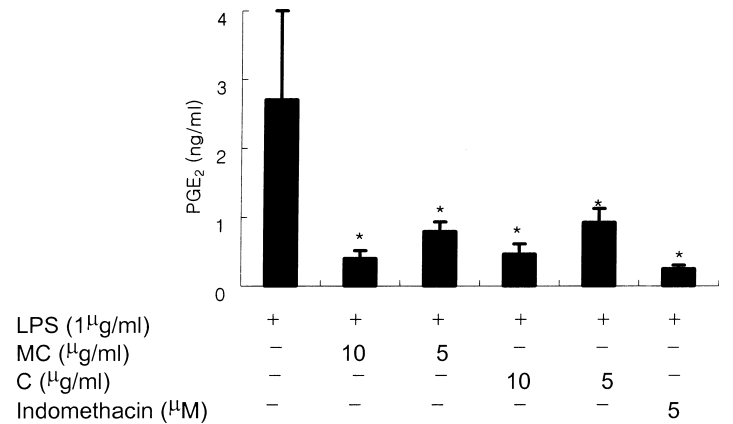

Fig. 2. Inhibitory Effect of CHD and MCHD on PGE2 Production of LPS-Stimulated RAW 264.7 Cellls

LPS, lipopolysaccharide; MC, metabolized Chunghyuldan; C, Chunghyuldan. All values are means \pm S.D. $(n=3)$. * Significantly different from LPS-stimulated group $(p<0.05)$.

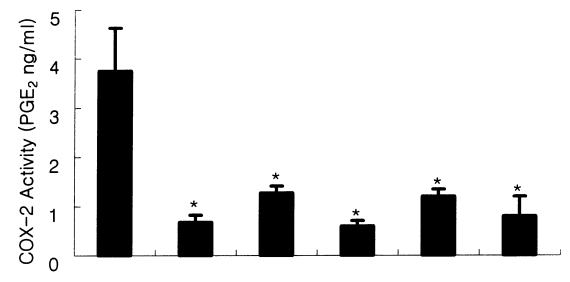

$\begin{array}{lcccccc}\operatorname{LPS}(1 \mu \mathrm{g} / \mathrm{ml}) & + & + & + & + & + & + \\ \mathrm{MC}\left(\mu_{\mathrm{g} / \mathrm{ml})}\right. & - & 10 & 5 & - & - & - \\ \mathrm{C}\left(\mu_{\mathrm{g}} / \mathrm{ml}\right) & - & - & - & 10 & 5 & - \\ \text { Indomethacin }\left(\mu_{\mathrm{M}}\right) & - & - & - & - & - & 5\end{array}$

Fig. 3. Inhibitory Effect of CHD and MCHD on COX-2 Activity of LPSStimulated RAW 264.7 Cellls

LPS, lipopolysaccharide; MC, metabolized Chunghyuldan; C, Chunghyuldan; LNMMA, $N^{\mathrm{G}}$-monomethyl-L-arginine. All values are means \pm S.D. $(n=3)$. $*$ Significantly different from LPS-stimulated group $(p<0.05)$.
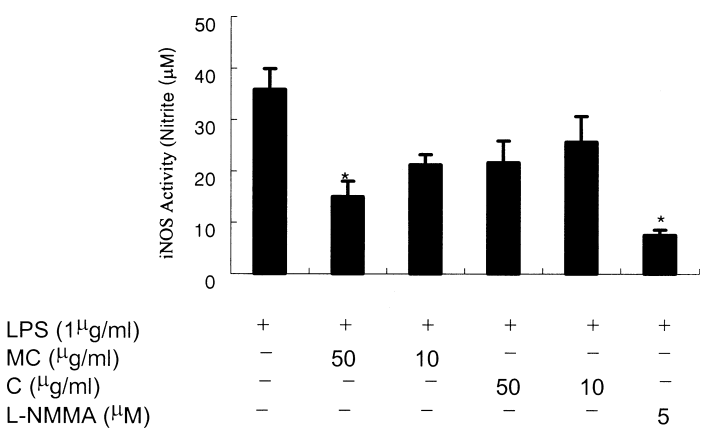

Fig. 4. Inhibitory Effect of CHD and MCHD on Inducible NO Synthase Activity of LPS-Stimulated RAW 264.7 Cellls

The RAW 264.7 cells were stimulated with LPS $(1 \mu \mathrm{g} / \mathrm{ml})$ for $16 \mathrm{~h}$, and the cells washed twice with PBS. These cells were incubated with test were incubated with test agents or L-NMMA for $16 \mathrm{~h}$, and then measured NO contents with Griess reagent. LPS, lipopolysaccharide; MC, metabolized Chunghyuldan; C, Chunghyuldan. All values are means \pm S.D. $(n=3)$. $*$ Significantly different from LPS-stimulated group $(p<0.05)$.

also increased the synthesis of PGE2 (Fig. 2). Both MCHD and CHD potently suppressed PGE2 production in a dose-dependent manner. Therefore inhibitory effect of CHD and MCHD on COX-2 activity was also investigated (Fig. 3). Both MCHD and CHD potently inhibited COX-2 enzyme activities at $10 \mu \mathrm{g} / \mathrm{ml}$. However, both CHD and MCHD weakly inhibit iNOS activity (Fig. 4). MCHD inhibited iNOS activity more potently than CHD.

Effect of CHD and MCHD on iNOS and COX-2 Protein Expression in LPS-Stimulated RAW 264.7 Cells Whether CHD could affect the iNOS and COX-2 protein

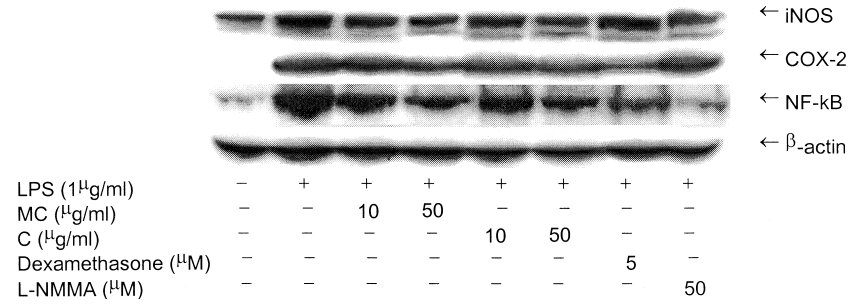

Fig. 5. Effect of CHD and MCHD on Protein Expressions of iNOS, COX2 and NF- $\kappa$ B in LPS-Stimulated RAW 264.7 Cellls

LPS, lipopolysaccharide; MC, metabolized Chunghyuldan; C, Chunghyuldan; LNMMA, $N^{\mathrm{G}}$-monomethyl-L-arginine.

expressions was also examined. Stimulation of the RAW 264.7 cells with LPS resulted in accumulation of the iNOS protein, as determined by Western blot analysis (Fig. 5). Both CHD and MCHD reduced the levels of the iNOS protein in a dose-dependent manner. Densitometer scans of the respective blots showed that CHD and MCHD at concentrations of 10 and $50 \mu \mathrm{g} / \mathrm{ml}$, the levels of the iNOS protein were reduced by 40 and $47 \%$, and 46 and $60 \%$ respectively, compared with the control cells stimulated with LPS. Those of MCHD were not significantly different to those of CHD. These amounts of iNOS protein correlated with the reduced accumulation of nitrite.

Stimulation of the RAW 264.7 cells with LPS also induced the expression of the COX-2 protein. Both CHD and MCHD reduced the levels of the COX-2 protein in a dose-dependent manner. The CHD and MCHD at concentrations of 10 and $50 \mu \mathrm{g} / \mathrm{ml}$ reduced the levels of the COX-2 protein by 22 and $33 \%$, and 34 and $45 \%$, respectively, compared with the control cells stimulated with LPS. These amounts of COX-2 protein expression were correlated with the reduced accumulation of the $\mathrm{PGE}_{2}$.

The effect of CHD and MCHD on the activation of the nuclear transcription factor NF- $\kappa \mathrm{B}$, which promotes both iNOS and COX-2 protein expressions, was investigated. The $\mathrm{NF}-\kappa \mathrm{B}$ in the nuclei fraction was activated by LPS. However, both CHD and MCHD inhibited the activation of the NF- $\kappa$ B in the RAW 264.7 cells stimulated with LPS. The CHD and MCHD at concentrations of 10 and $50 \mu \mathrm{g} / \mathrm{ml}$ reduced the levels of the activated NF- $\kappa$ B by 52 and $59 \%$, and 54 and $65 \%$, respectively, compared with the control cells stimulated with LPS. The amounts of activated NF- $\kappa \mathrm{B}$ were correlated with the reduced accumulation of the iNOS and COX-2 proteins. Particularly, MCHD-inhibitory activity was more potent than that of CHD.

\section{DISCUSSION}

Most herbal medicines are administered orally as decoctions. Their components are therefore inevitably brought into contact with intestinal microflora in the alimentary tract. The intestinal bacteria may transform these components before they were absorbed from the gastrointestinal tract. Studies on the metabolism of the components by human intestinal microflora are of a great importance to an understanding of their biological effects. ${ }^{15,16)}$ The constituents of CHD was also metabolized by human intestinal microflora. The transforamition increased antioxidant action of CHD. Therefore, we metabolized CHD and compared its anti-inflammatory 
effect to that of metabolized CHD.

The inflammatory reactions are modulated by macrophages as well as neutrophils. NO and prostaglandins are two pleiotropic mediators produced at inflammatory sites by constitutive and inducible NO synthases and COX-1 and COX-2." Both CHD and MCHD potently inhibited the PGE2 and NO biosynthesis in LPS-stimulated RAW 264.7 cells. These did not only inhibit the activities of COX-2 and iNOS, but also inhibited the activation of NF- $\kappa \mathrm{B}$ transcription factor, which should regulate the iNOS and COX-2 gene expressions, on the RAW 264.7 cells stimulated with LPS. The inhibitory activity of MCHD was more potent than that of CHD. These results suggest that CHD and MCHD may express antiinflammatory activity by the direct inhibition of COX-2 and iNOS enzyme activities and the regulation of the signal transduction related to the activation of NF- $\kappa \mathrm{B}$.

CHD contained a lot of components, which can be also metabolized by intestinal microflora in human intestine. The constituents of the metabolized CHD, thus MCHD, may be easily absorbed into blood rather than those of CHD. For example, baicalein could be absorbed into the blood, and express antiinflammaotry action. Based on these findings, we believe that in vivo pharmacological activity of CHD may be similar to that of MCHD, and CHD may show potent anti-inflammatory activity, and improve brain ischemia.

\section{REFERENCES}

1) Barber P. A., Demchuk A. M., Hirt L., Buchan A. M., Adv. Neurol., 92, 151-164 (2003).

2) Bartosik-Psujek H., Belniak E., Stelmasiak Z., Neurol. Sci., 24, 279280 (2003).

3) Appleton I., Tomlinsom A., Willoughby D. A., Adv. Pharmacol., 35, 27-78 (1996).

4) Stefanovic-Racic S., Stadler J., Evans C. H., Arthritis Rheum., 36, 1036-1044 (1993).

5) MacMicking J. D., Xie Q. W., Nathan C., Ann. Rev. Immunol., 15, $323-350$ (1997).

6) Smith W. L., Garavito R. M., DeWitt D. L., J. Biol. Chem., 271, 33157-33160 (1996).

7) Dubois R. N., Abramson S. B., Crofford L., Gupta R. A., Simon L. S., Van De Putte L. B. A., Lipsky P. E., FASEB J., 12, 1063-1073 (1998).

8) Perkins D. J., Kniss D. A., J. Leukoc. Biol., 65, $792-799$ (1999).

9) Kim Y. S., Jung E. A., Shin J. E., Chang J. C., Yang H. K., Kim N. J., Cho K. H., Kim D.-H., Biol. Pharm. Bull., 25, 1442-1445 (2002).

10) Yang H. K., Kim Y. S., Bae H. S., Cho K. H., Shin J. E., Kim N. J., Kim D.-H., Nat. Prod. Sci., 9, 38-43 (2003).

11) Jung W. S., Am. J. Chin. Med., in press (2004).

12) Xiong Q., Kadota S., Tani T., Namba T., Chem. Pharm. Bull., 19, $1580-1585$ (1996).

13) Choi O. H., Kim J. H., Kinet J. P., Nature (London), 380, 634-636 (1996).

14) Ishihara T., Kohno K., Ushio S., Iwaki K., Ikeda M., Kurimoto M., Eur. J. Pharmacol., 407, 197-204 (2000).

15) Kim D.-H., Nat. Prod. Sci., 8, 35-43 (2002).

16) Kobashi K., Akao T., Bifidobacteria Microflora, 16, 1-7 (1997). 